\section{REVIEW SUMMARY}

\section{NOISE POLLUTION}

\section{The soundscape of the Anthropocene ocean}

\section{Carlos M. Duarte*, Lucille Chapuis, Shaun P. Collin, Daniel P. Costa, Reny P. Devassy, Victor M. Eguiluz, Christine Erbe, Timothy A. C. Gordon, Benjamin S. Halpern, Harry R. Harding, Michelle N. Havlik, Mark Meekan, Nathan D. Merchant, Jennifer L. Miksis-OIds, Miles Parsons, Milica Predragovic, Andrew N. Radford, Craig A. Radford, Stephen D. Simpson, Hans Slabbekoorn, Erica Staaterman, Ilse C. Van Opzeeland, Jana Winderen, Xiangliang Zhang, Francis Juanes}

BACKGROUND: Sound is the sensory cue that travels farthest through the ocean and is used by marine animals, ranging from invertebrates to great whales, to interpret and explore the marine environment and to interact within and among species. Ocean soundscapes are rapidly changing because of massive declines in the abundance of sound-producing animals, increases in anthropogenic noise, and altered contributions of geophysical sources, such as sea ice and storms, owing to climate change. As a result, the soundscape of the Anthropocene ocean is fundamentally different from that of preindustrial times, with anthropogenic noise negatively impacting marine life.

ADVANCES: We find evidence that anthropogenic noise negatively affects marine animals.
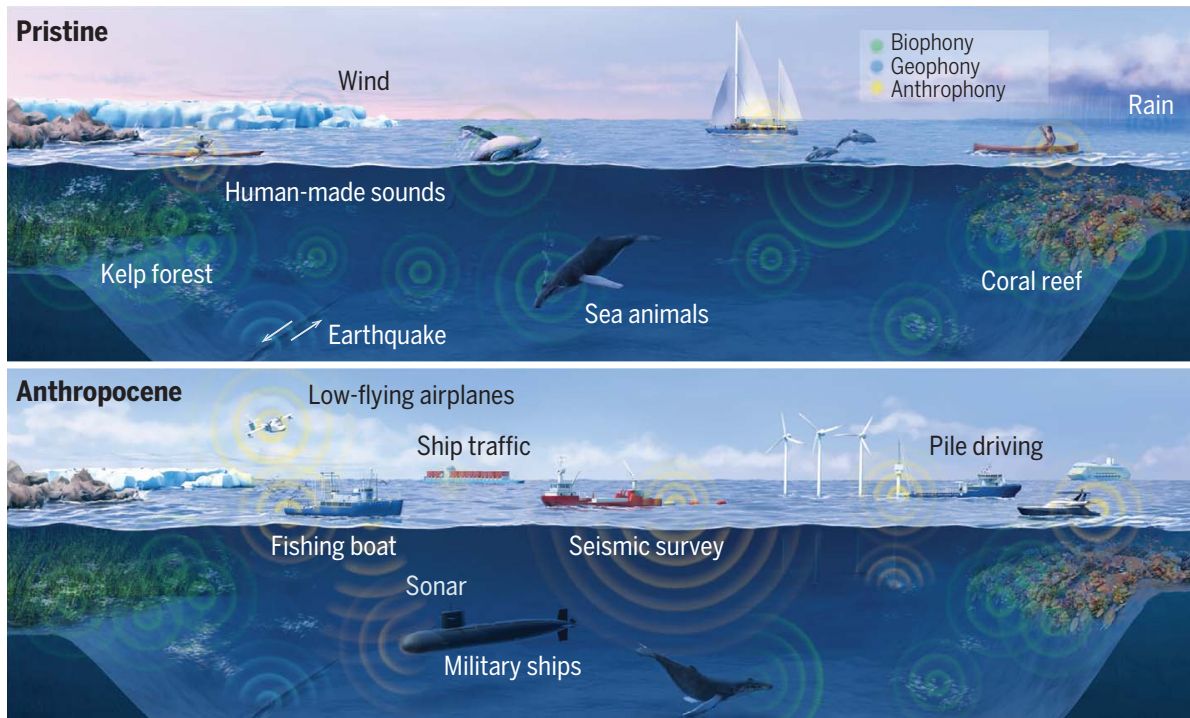

Poorly managed future

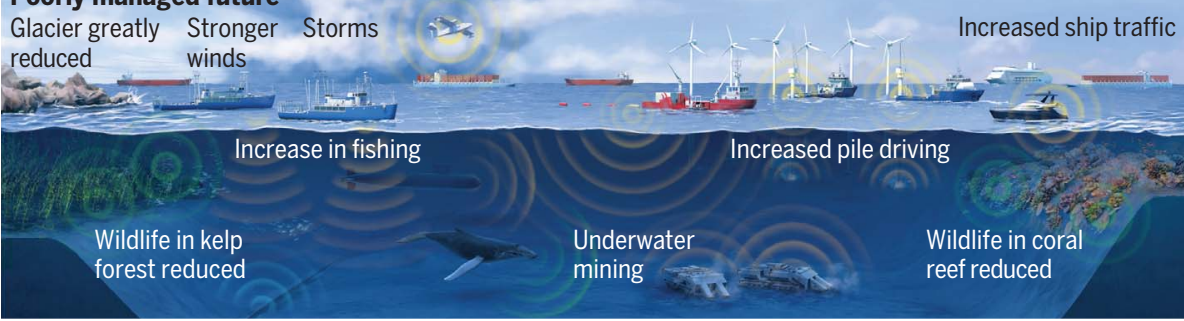

Well-managed future

Less ship traffic Quieter propellers

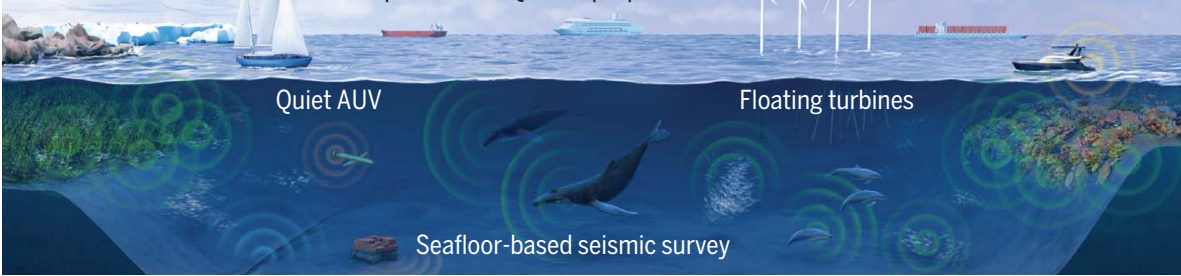

Strong evidence for such impacts is available for marine mammals, and some studies also find impacts for fishes and invertebrates, marine birds, and reptiles. Noise from vessels, active sonar, synthetic sounds (artificial tones and white noise), and acoustic deterrent devices are all found to affect marine animals, as are noise from energy and construction infrastructure and seismic surveys. Although there is clear evidence that noise compromises hearing ability and induces physiological and behavioral changes in marine animals, there is lower confidence that anthropogenic noise increases the mortality of marine animals and the settlement of their larvae.

OUTLOOK: Anthropogenic noise is a stressor for marine animals. Thus, we call for it to be included in assessments of cumulative pressures on marine ecosystems. Compared with other stressors that are persistent in the environment, such as carbon dioxide emitted to the atmosphere or persistent organic pollutants delivered to marine ecosystems, anthropogenic noise is typically a point-source pollutant, the effects of which decline swiftly once sources are removed. The evidence summarized here encourages national and international policies to become more ambitious in regulating and deploying existing technological solutions to mitigate marine noise and improve the human stewardship of ocean soundscapes to maintain a healthy ocean. We provide a range of solutions that may help, supported by appropriate managerial and policy frameworks that may help to mitigate impacts on marine animals derived from anthropogenic noise and perturbations of soundscapes.

The list of author affiliations is available in the full article online. *Corresponding author. Email: carlos.duarte@kaust.edu.sa Cite this article as C. M. Duarte et al., Science 371, eaba4658 (2021). DOI: 10.1126/science.aba4658 https://doi.org/10.1126/science.aba4658

Changing ocean soundscapes. The illustrations from top to bottom show ocean soundscapes from before the industrial revolution that were largely composed of sounds from geological (geophony) and biological sources (biophony), with minor contributions from human sources (anthrophony), to the present Anthropocene oceans, where anthropogenic noise and reduced biophony owing to the depleted abundance of marine animals and healthy habitats have led to impacts on marine animals. These impacts range from behavioral and physiological to, in extreme cases, death. As human activities in the ocean continue to increase, management options need be deployed to prevent these impacts from growing under a "businessas-usual" scenario and instead lead to well-managed soundscapes in a future, healthy ocean. AUV, autonomous underwater vehicle. 


\section{REVIEW}

\section{NOISE POLLUTION}

\section{The soundscape of the Anthropocene ocean}

\author{
Carlos M. Duarte ${ }^{1,2 *}$, Lucille Chapuis ${ }^{3}$, Shaun P. Collin ${ }^{4}$, Daniel P. Costa ${ }^{5}$, Reny P. Devassy ${ }^{1}$, \\ Victor M. Eguiluz ${ }^{6}$, Christine Erbe ${ }^{7}$, Timothy A. C. Gordon ${ }^{3,8}$, Benjamin S. Halpern ${ }^{9,10}$, \\ Harry R. Harding ${ }^{11}$, Michelle N. Havlik ${ }^{1}$, Mark Meekan ${ }^{8}$, Nathan D. Merchant ${ }^{12}$, \\ Jennifer L. Miksis-OIds ${ }^{13}$, Miles Parsons ${ }^{8,7}$, Milica Predragovic ${ }^{1}$, Andrew N. Radford ${ }^{11}$, \\ Craig A. Radford ${ }^{14}$, Stephen D. Simpson ${ }^{3}$, Hans Slabbekoorn ${ }^{15}$, Erica Staaterman ${ }^{16}$, \\ Ilse C. Van Opzeeland ${ }^{17}$, Jana Winderen ${ }^{18}$, Xiangliang Zhang ${ }^{19}$, Francis Juanes ${ }^{20}$
}

Oceans have become substantially noisier since the Industrial Revolution. Shipping, resource exploration, and infrastructure development have increased the anthrophony (sounds generated by human activities), whereas the biophony (sounds of biological origin) has been reduced by hunting, fishing, and habitat degradation. Climate change is affecting geophony (abiotic, natural sounds). Existing evidence shows that anthrophony affects marine animals at multiple levels, including their behavior, physiology, and, in extreme cases, survival. This should prompt management actions to deploy existing solutions to reduce noise levels in the ocean, thereby allowing marine animals to reestablish their use of ocean sound as a central ecological trait in a healthy ocean.

S oundscapes, defined as "ambient sound in terms of its spatial, temporal, and frequency attributes, and the types of sources contributing to the sound field" (I), are changing rapidly in the Anthropocene. In contrast to the long-standing recognition of the effects of anthropogenic sound in terrestrial systems (2), the impacts of changing ocean soundscapes on marine animals have received relatively limited attention. This neglect percolates reviews of cumulative stressors

\footnotetext{
Red Sea Research Centre (RSRC) and Computational Bioscience Research Center (CBRC), King Abdullah University of Science and Technology, Thuwal 23955, Saudi Arabia ${ }^{2}$ Arctic Research Centre, Department of Biology, Aarhus University, C.F. Møllers Allé 8, DK-8000 Århus C Denmark. ${ }^{3}$ Biosciences, University of Exeter, Prince of Wales Road, Exeter EX4 4PS, UK. ${ }^{4}$ School of Life Sciences, La Trobe University, Bundoora, VIC 3086, Australia. ${ }^{5}$ Institute of Marine Sciences, University of California, Santa Cruz, CA 95060, USA ${ }^{6}$ Instituto de Física Interdisciplinar y Sistemas Complejos IFISC (CSIC-UIB), E07122 Palma de Mallorca, Spain. 'Centre for Marine Science \& Technology, Curtin University, Perth, WA 6102, Australia. ${ }^{8}$ Australian Institute of Marine Science, Perth, WA 6009, Australia. ${ }^{9}$ National Center for Ecological Analysis and Synthesis, University of California, Santa Barbara, CA 93101, USA. ${ }^{10}$ Bren School of Environmental Science and Management, University of California, Santa Barbara, CA 93106, USA. ${ }^{11}$ School of Biological Sciences, University of Bristol, 24 Tyndall Avenue, Bristol BS8 1TQ. UK. ${ }^{12}$ Centre for Environment, Fisheries and Aquaculture Science, Lowestoft NR33 OHT, UK. ${ }^{13}$ Center for Acoustics Research and Education, University of New Hampshire Durham, NH 03824, USA ${ }^{14}$ Institute of Marine Science, Leigh Marine Laboratory, University of Auckland P.0. Box 349, Warkworth 0941, New Zealand. ${ }^{15}$ Institute of Biology, Leiden University, P. 0. Box 9505, 2300 RA Leiden, Netherlands. ${ }^{16}$ Beneath the Waves, P.O. Box 126, Herndon, VA 20172, USA. ${ }^{17}$ Alfred-Wegener Institute for Polar and Marine Research, Am Handelshafen 12,27570 Bremerhaven, Germany. ${ }^{18}$ Schweigaardsgate 80, 0656 Oslo, Norway. ${ }^{19}$ Computer, Electrical and Mathematical Science and Engineering Division, King Abdullah University of Science and Technology, Thuwal 23955, Saudi Arabia. ${ }^{20}$ Department of Biology, University of Victoria, Victoria, BC, Canada.

*Corresponding author. Email: carlos.duarte@kaust.edu.sa
}

$(3,4)$ and drivers of global change in the ocean $(5,6)$, as well as scientific assessments (7) and policy frameworks [United Nations Convention on Biological Diversity (UNCBD), UN Convention for the Law of the Sea (UNCLOS), UN Sustainable Development Goals (UN SDGs)] aimed at improving ocean conservation and sustainability. Given the rapid pace of change in ocean soundscapes, we argue that there is an urgent need to assess the evidence for impacts of anthropogenic noise on marine life, which will enable policy frameworks to mitigate human impacts on ocean soundscapes as a necessary foundation for a healthy ocean.

Here, we review how the changing ocean soundscape of the Anthropocene is affecting marine life. We do so by first summarizing our current understanding of the importance of sound to marine animals and the components and ecological relevance of undisturbed ocean soundscapes. We show how ocean soundscapes are changing in the Anthropocene and assess, on the basis of a systematic review of four decades of published research, the evidence for the resulting impacts on marine animals. We then discuss how available solutions, if supported by appropriate managerial and policy frameworks, may help mitigate impacts on marine animals that arise from anthropogenic noise and perturbations of soundscapes.

\section{Hearing the ocean soundscape}

Sound propagates relatively fast and far under water, carrying information over greater spatial scales than most other sensory cues such as light or chemicals (8). As a result, marine animals have evolved a wide range of receptors to detect sound, which have been well studied for marine mammals but have been only recently described for invertebrates, such as jellyfish $(9,10)$ (Fig. 1). Hearing in marine animals (Fig. 1) ranges from marine invertebrates, fishes, and reptiles, which perceive sounds of relatively low frequency (generally $<5 \mathrm{kHz}$ ), to cetaceans, which can detect highfrequency (up to $200 \mathrm{kHz}$ ) sound (Figs. 1 and $2 \mathrm{~B})$. The hearing range of marine animals is a key determinant of their potential responses to different components of ocean soundscapes and their vulnerability to impacts from different sources of underwater noise (Fig. 2B).

Before the Industrial Revolution, ocean soundscapes were largely composed of sounds from geological (geophony) and biological sources, produced both intentionally and unintentionally (biophony), with minor contributions from human sources (anthrophony). Understanding the contexts and relative contributions of these sound sources provides key insights into how anthropogenic changes to ocean soundscapes may affect marine life and the overall health of the ocean.

Weather conditions and geological processes make important contributions to marine soundscapes. Wind blowing over the ocean, waves breaking, rain or hail falling onto the sea surface, and gas bubbles vibrating, rising, and bursting at the surface all generate characteristic sound spectra [(11, 12); Fig. 2A]. In polar regions, seasonal processes like ice melting, pressure cracking, and iceberg calving dominate soundscapes (13), and noise from earthquakes, undersea volcanoes, and hydrothermal vent activity (14) potentially propagate thousands of kilometers [(15); Fig. 2A]. Each of these geophonic components produces sound over different frequencies and spatial and temporal scales (Fig. 2A), which is, therefore, perceived differently by various types of animals (Fig. 2B),

Marine animals intentionally produce sounds ranging from infrasonic $(<20 \mathrm{~Hz})$ to ultrasonic $(>20 \mathrm{kHz})$, although most are emitted between $10 \mathrm{~Hz}$ and $20 \mathrm{kHz}$ and are audible to a wide range of taxa (Fig. 2B). These sounds may be frequency and/or amplitude modulated and can be emitted as single pulses or occur in regular sequences or temporal patterns, such as pulse trains of fish calls and melodic phrases of whale songs. The continuous singing of single individuals, the gregarious chorusing of a group, or the collective sounds of some animals foraging or moving (e.g., urchins or crabs across a reef) can increase sound levels in particular frequency bands. Biophony may also be modulated by changes in weather, currents, and other factors, exemplified by the cessation of fish chorusing due to the passage of a hurricane (16).

Animals produce sounds for a range of reasons, including navigation, foraging, agonistic displays, territorial defense, mate attraction, and reproductive courtship (17-19). For example, 
Particle motion

Detector element
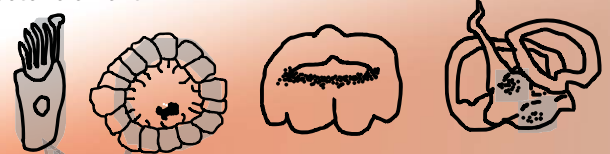

Agnathans (hagfishes, lampreys)

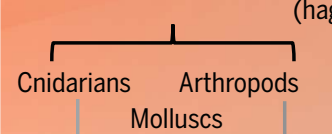

Chondrichthyans (sharks, rays)

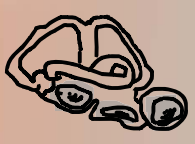

Osteichthyans (bony fishes)
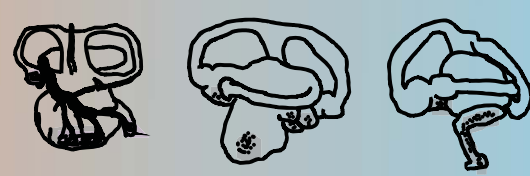

Amphibians
Pressure

\section{Scientific discoveries (2500 y)}

Fig. 1. Evolution of hearing under water and timeline of scientific advances. Evolution and timeline events are from (129). Hair cells as a mechanosensory receptor for hearing appeared early in the evolution of animals (10), evolving from invertebrate statocysts, which detect gravity and vibrations underwater, to fish ears, which perceive sounds of relatively low frequency $(<5 \mathrm{kHz})$. Some bony fishes (Osteichthyes) have evolved ancillary hearing structures that connect the ear with the swim bladder, increasing hearing bandwidth and sensitivity (25). When marine tetrapods moved onto land, acoustic organs, adapted to hearing sound as pressure waves (89), evolved to compensate for communication in air, a lower-density medium, which slowed the movement of sound waves relative to water. Impedance-matching structures, or tympanic middle ears, appeared independently in reptiles, birds, and mammals (90), increasing the overall sensitivity of hearing to exceed, in some mammals, $50 \mathrm{kHz}$. Further changes in the pressure-sensing ear occurred as reptiles and mammals returned to the ocean (130). In toothed whales, the middle ear evolved to receive sound passing through the fatty tissues in the jaws, an effective means of conduction that increases the upper hearing limit of these mammals to $200 \mathrm{kHz}$ (131). Ma, million years ago; $y$, years. male toadfish guard benthic nests and produce "hums" to attract females, rendering these sounds key components of some night-time soundscapes [e.g., $(20,21)]$. Fishes-such as Atlantic cod (Gadus morhua), croakers (Sciaenidae), and groupers (Serranidae)-use sounds to gather in large aggregations and coordinate spawning activities (22-24). Marine mammals use vocal communication to aid in mating, rearing of young, and group cohesion, among other social (25) and feeding functions (26). Pinnipeds produce sounds both in air and under water that are associated with territorial and mating behavior, particularly during the breeding season (27). Bearded seals (Erignathus barbatus), for example, produce frequencymodulated trills, which are a major component of Arctic soundscapes in spring (28). Baleen whales produce low-frequency reproductive and social calls that can travel across ocean basins (29), with humpback whales 


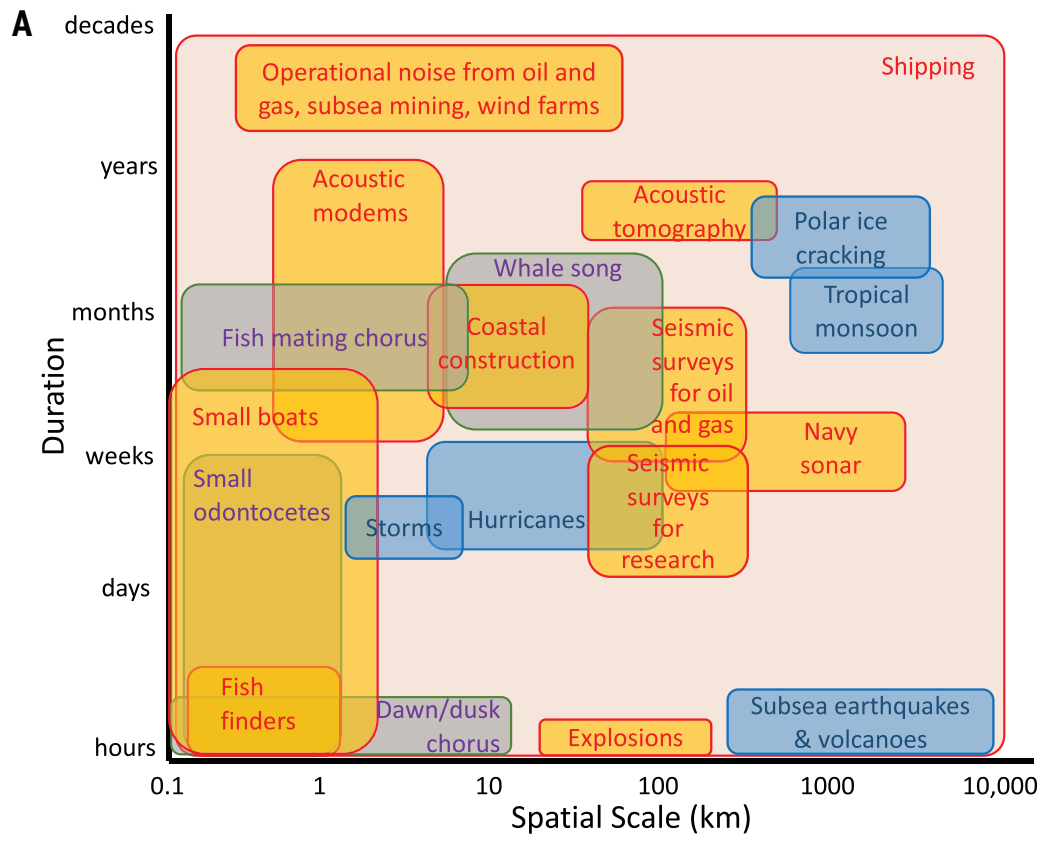

B
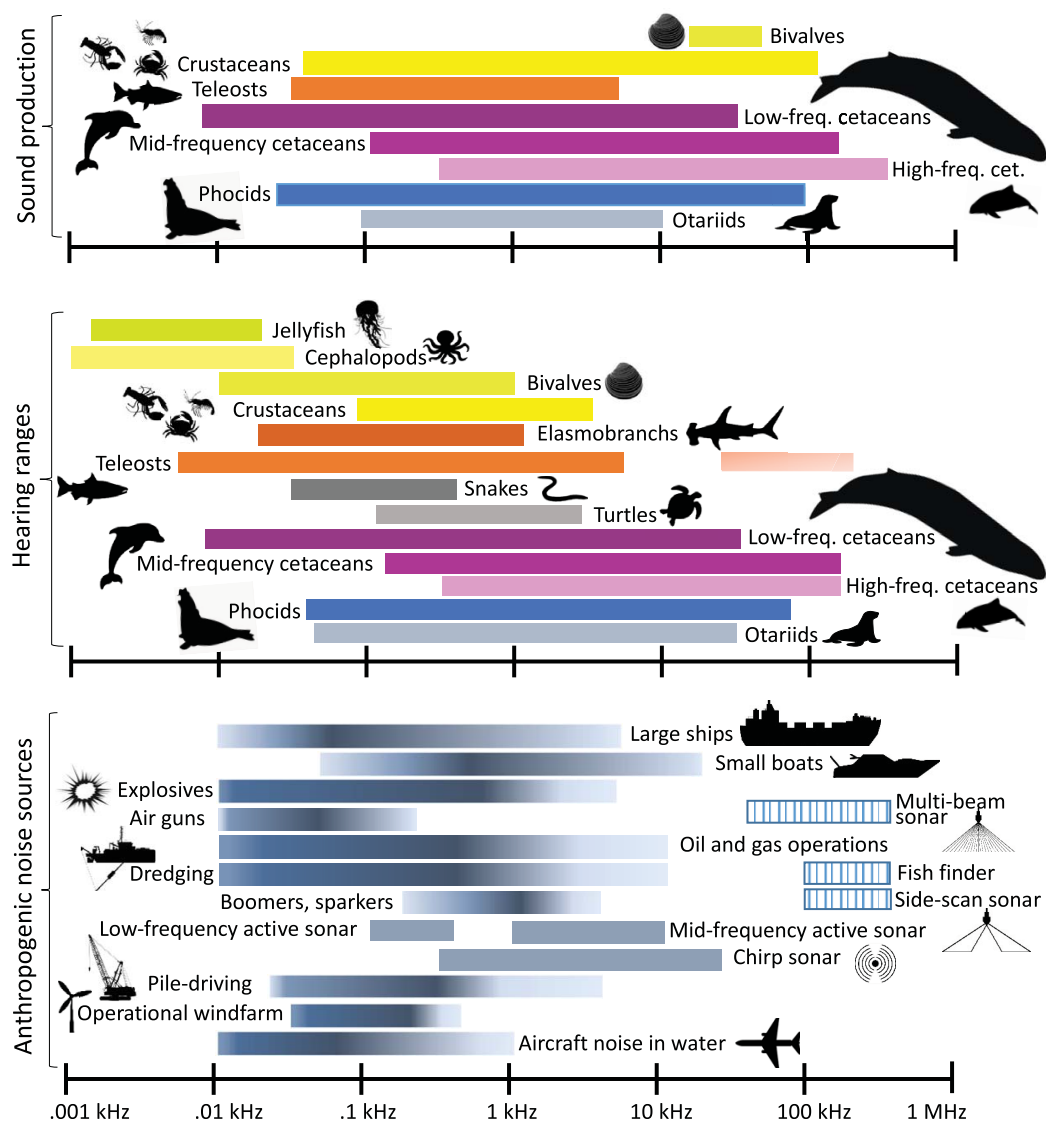

Fig. 2. Sources and animal receivers of sound in the ocean soundscape.

(A) Stommel diagram showing the spatial extent and duration of selected biophony (rounded gray squares), geophony (rounded blue squares), and anthrophony (rounded yellow squares) events. Events (rounded squares) reflect the spatial and temporal period over which signals or bouts of signals typically occur. Although some sound sources, such as those used in hydrographic surveys, do not propagate particularly far, survey efforts can cover a large spatial extent (an entire Exclusive Economic Zone). "Dawn/dusk chorus" refers to the daily sounds produced by a collection of species (e.g., fish, snapping shrimp). Shipping noise encompasses the full range of spatial and temporal scales. (B) Approximate sound production and hearing ranges of marine taxa and frequency ranges of selected anthropogenic sound sources. These ranges represent the acoustic energy over the dominant frequency range of the sound source, and color shading roughly corresponds to the dominant energy band of each source. Dashed lines represent sonars to depict the multifrequency nature of these sounds. Sources for the data displayed in the figures are $(9,18,25,53,75,83,131-139)$. 
(Megaptera novaeangliae) singing complex songs as part of male reproductive displays that have regional dialects and change over time (30).

Marine animals also produce mechanical sounds, such as those produced by the impact of different body parts on environmental substrates (e.g., breaching, tail slaps), which often convey information about body mass and size (31) and movement and foraging behaviors $(32,33)$. Sea urchins and parrotfishes, for example, make scraping or crunching sounds as a by-product of foraging that occur in predictable peaks associated with tidal or diurnal cycles $(34,35)$. Other animals use sound to forage. Snapping shrimps produce a "snap" sound to stun prey, which creates a loud "crackling" sound that is present in many coastal habitats that support dense colonies of these shrimps (36). Odontocetes, such as sperm whales (Physeter macrocephalus) and various species of dolphins and porpoises, also possess sophisticated biosonar systems that produce sounds to echolocate, select, and pursue prey under water (26).

The diversity, composition, and density of the biophonic community are key components of the soundscape ecology paradigm, which seeks to identify habitats and assess their health status using sound. An ecological role for ocean soundscapes is supported by the fact that many species use ocean soundscapes as a cue to find their habitats at key life stages. For example, larvae and juveniles of some invertebrate and vertebrate reef species use soundscapes as a navigational cue to locate suitable settlement habitats (37). Indeed, the distinctive sound-producing structures or organs of marine animals provide, in many cases, an acoustic fingerprint that aids their identification within soundscapes, allowing for inferences on their identity, behavior, and sometimes relevant life history and physical traits (38-40).

Advances in acoustic-recording technology allow ocean soundscapes to be characterized for longer periods of time and at greater depths than previously possible (36). In parallel, new tools for soundscape analysis facilitate both species-specific call recognition and summative approaches to resolve the entire acoustic spectrum. Despite this progress, the paradigm that soundscapes can be used as proxies for ecosystem health, developed for terrestrial ecosystems (41), has been applied to the marine environment with only limited success [e.g., (42, 43)]. In some cases, sound-pressure levels in low frequencies correlate positively with visual measures of fish diversity, coral cover, and invertebrate abundance $(44,45)$. Efforts to reduce the dimensionality of a complex soundscape to a single number that reflects the diversity or complexity of a soundscape [e.g., (46)] may provide useful biological information $(27,42)$ but cannot be readily generalized, because the results obtained are highly sensitive to parameterization (47). Instead, multiple indices relating to characteristics of individual sounds can be combined to provide an indication of the contribution of particular sound types (48). Overall, assessments of ocean soundscapes demonstrate a growing contribution of human activities across the ocean (Fig. 3).

\section{The soundscape of the Anthropocene ocean}

Human activity has altered biophony and geophony and has, either deliberately or as a by-product, added an increasingly prevalent third component-anthrophony-across a broad range of frequencies to ocean soundscapes (2) (Fig. 2B). Examples of deliberate human use of marine sound include seismic surveys that produce high-energy, low-frequency, shortduration sounds aimed at detecting the presence of petroleum and gas deposits below the seafloor, as well as multibeam echosounders and side-scan sonars that generally produce high-frequency sounds to map the seabed and
A

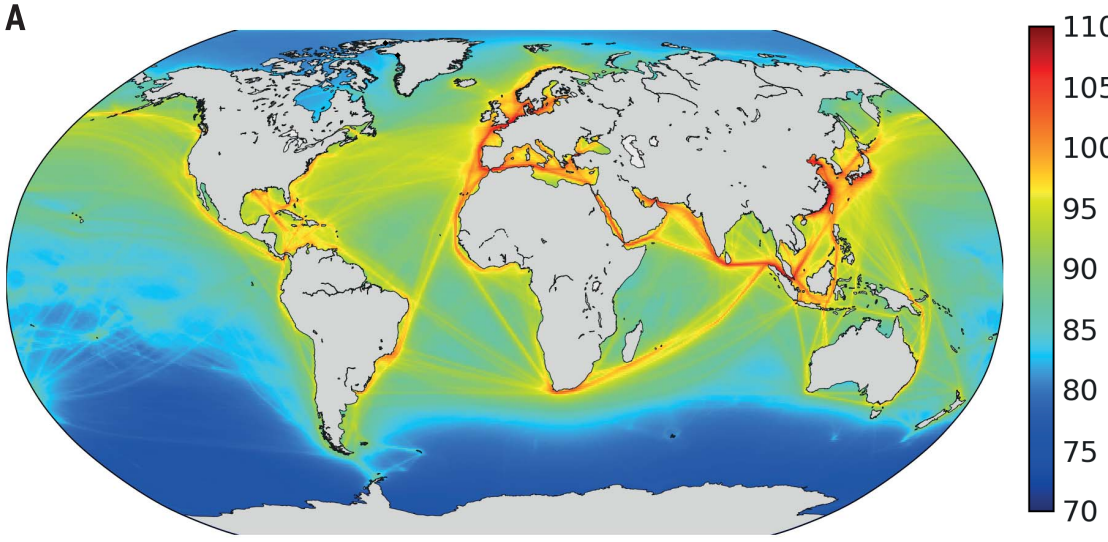

C

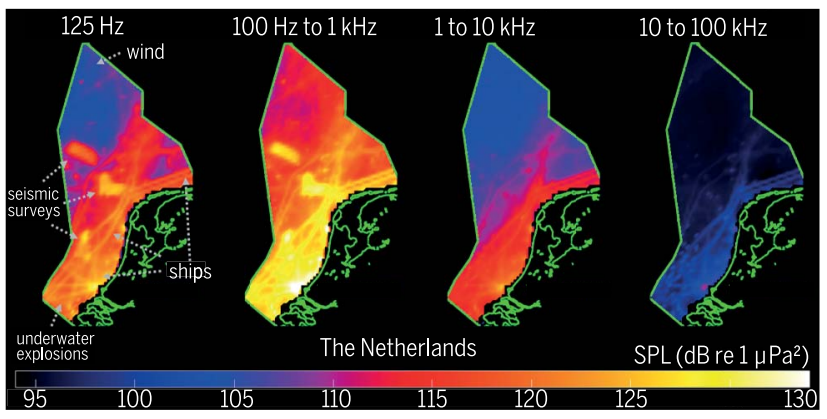

B
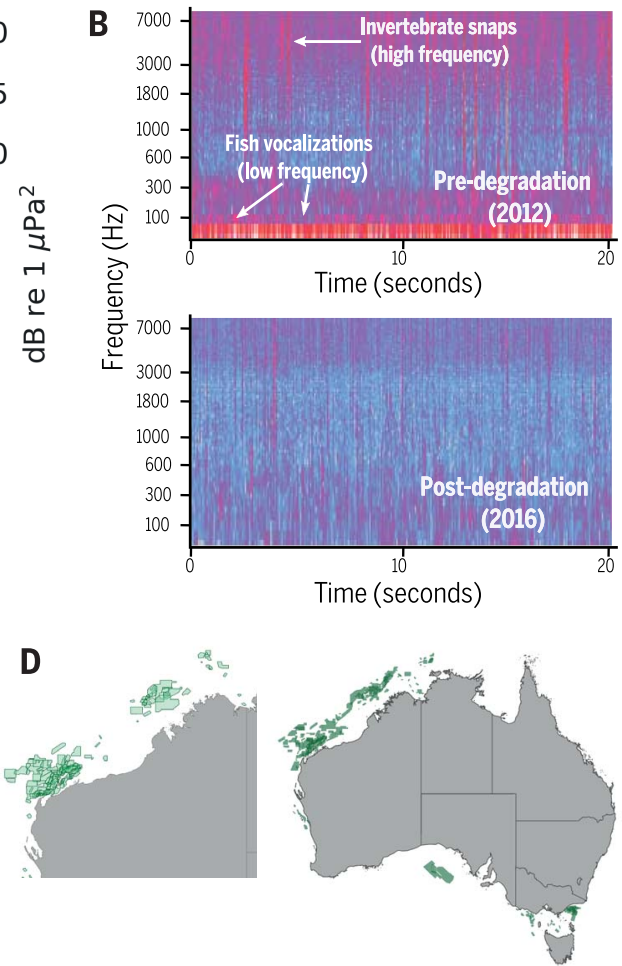

Fig. 3. Human pressures have altered ocean soundscapes at scales ranging from local to global. (A) Average sound level estimated globally from marine traffic (at $100 \mathrm{~Hz}$ ), based on average shipping activity directed from automatic identification system (AIS) data for 2014. (B) Sound-pressure levels pre- and postdegradation at sites around Lizard Island in the Great Barrier Reef (62). (C) Sound levels in four different frequency bands in the Dutch North Sea, averaged over 2 years [adapted from (140)]. (D) Boundaries of three-dimensional seismic surveys in northwest Australia (left) and seismic lines of two-dimensional surveys in all Australian waters (right) since 1973 (data from wapims.dmp.wa.gov.au/wapims and https://nopims.dmp.wa.gov.au/nopims). 
detect organisms and particles in the water column. These sensing techniques are, at times, a major component of present ocean soundscapes in many areas, especially those holding oil and gas reservoirs $(49,50)$, such as the continental shelf of northwestern Australia and the North Sea (Fig. 3D). Across the ocean, scientific surveys use similar tools to map the seabed and identify geological features, fishers use "fish finders" to search for schools of fish, and navies use active sonars across a range of frequencies to detect submarines and other targets.

Much of anthrophony is an unintended byproduct of human activities (Figs. 2 and 3), which are intensifying across the ocean. Over the past 50 years, increased shipping has contributed an estimated 32-fold increase in the low-frequency noise present along major shipping routes (51) (Figs. 2 and 3). Vessel noise is prominent in many ocean regions even away from major shipping lanes, owing to long-range sound propagation at low frequencies, although some areas display stable or even decreasing sound levels in targeted frequency bands (52). Whereas vessel noise does not propagate as far in shallow coastal waters, the higher vessel concentration often increases noise considerably above ambient levels in coastal regions.

Further anthrophony comes as an unintended by-product of less frequent, but still common, human activities associated with coastal development and resource extraction. Traffic on structures like bridges and airplanes flying at low altitude over the ocean produce low-level, continuous noise that can penetrate under water (53). Pile-driving during the construction of offshore wind farms can substantially increase local sound levels (54), but the operational noise of turbines tends to attenuate below ambient levels of natural sound within a few hundreds of meters of wind farms (55). Similarly, construction and operation of oil and gas infrastructure (e.g., platforms, pipelines) increase anthrophony (56). The dynamic positioning systems (i.e., propellers and thrusters) used to maintain the position of offshore structures, such as drilling platforms, produce low-frequency noise (57). Technology that scrapes the bottom of the ocean-whether dredging the seafloor, harvesting minerals, or trawling for fisheriesalso generates low-frequency noise (58). Dynamite fishing, designed to stun or kill reef fish for easy collection, remains a major source of blasting noise in Southeast Asia and coastal Africa, and controlled detonation of bombs dropped on the seafloor during World War II continues, more than 70 years later, to be a major source of disruptive and destructive sound in the North Sea (Figs. 2 and 3). Explosions of mines, missiles, and bombs during naval warfare or military exercises also repre- sent a source of destructive sound. On a small scale, even coastal recreational activitiessuch as small motorboats, swimming, SCUBA diving, surfing, paddling, flying unmanned aerial vehicles (drones), or fireworks-contribute anthrophony to marine soundscapes (59-61).

Humans have also profoundly altered biophony and geophony in ocean soundscapes. Hunting of large marine animals, particularly highly vocal whales and pinnipeds, which began hundreds of years ago, has led to reduced and less diverse biophony in ocean soundscapes of the present. Sound levels of natural soundscapes decrease with the degradation of kelp forests, seagrass beds, coral reefs, and sponge beds, owing to fewer vocalizing animals (62-66). Biophony may also be reduced where soundscapes are heavily polluted by anthrophony as animals cease vocalizing or are displaced from ecosystems.

Climate change is increasing the number of cyclones and marine heatwaves that degrade marine habitats, which, in turn, may alter biophony. For example, degradation of coral reefs associated with these events dramatically changes ambient soundscapes, with the altered composition of the biotic community reflected in reduced overall acoustic energy and the complexity and diversity of reef soundscapes (46). Changes in the distributions of species with ocean warming also shift biophony. For example, reduced sea ice in the Arctic allows the range expansion of temperate whale species that compete for acoustic niche space with Arctic species, such as beluga whales (Delphinapterus leucas) (67). In addition, climate change directly affects the temperature, heat content, and stratification of the ocean, with sound traveling faster in a warmer ocean, to the extent that long-range acoustic transmissions have been used to measure large-scale ocean temperature and heat content-a phenomenon that W. Munk termed "the sound of climate change" (68). Ocean warming also affects geophony in polar areas through decreasing sea ice cover, with the soundscape of a progressively ice-free Arctic Ocean departing from that of the ice-covered Arctic Ocean of the past $(69,70)$. High sound levels occur during periods of ice formation, whereas polar soundscapes are very quiet in the high-frequency range during periods of solid ice coverage (71). Ice-free waters will also likely lead to increased anthrophony through greater ease of human access and activity (shipping, fishing, and seismic surveys) in a warming Arctic Ocean. An increased inflow of shallow "tongues" of warm, salty Pacific and Atlantic waters into the Arctic Ocean is also dramatically altering the acoustic environment by creating a local maximum in the sound speed profile at the depths between 100 and $200 \mathrm{~m}$. This water layer acts as a strong acoustic duct, channeling sound across dis- tances of 80 to $100 \mathrm{~km}$ (69), with comparable effects reported in coastal areas receiving glacial melt waters. In the tropics, climate change may increase geophony levels because of increased winds, rainfall on the surface, and waves as the energy of tropical storms increases. Greenhouse gas emissions also change sound propagation in the ocean by decreasing $\mathrm{pH}$ as $\mathrm{CO}_{2}$ levels increase, which is expected to lead to a noisier ocean, owing to substantial decreases in ocean sound absorption for frequencies lower than about $10 \mathrm{kHz}(72,73)$.

\section{Impacts of altered soundscapes in the Anthropocene ocean}

Initial awareness of the impacts of the altered soundscapes of the Anthropocene ocean on marine life derived from evidence of injuries from high-intensity noise. This initial evidence focused on large iconic marine mammals (25) but has been expanded to include links between noise from military sonar, air guns, submarine explosions, and seismic surveys and hearing disabilities, mass strandings, and mortality of a number of marine animals (table S2).

Research on the ecological impacts of anthrophony has expanded to address the pervasive and prevalent impacts of chronic exposure to noise across vast spans of the ocean [table S2; (74)] and the potential impacts of anthropogenic noise on fishes (75-79), invertebrates $(80,81)$, and whole marine ecosystems (82). Anthropogenic noise can interfere with natural auditory signal processing by marine animals, an effect termed "masking" (83), which reduces their communication space [see (84) for marine mammals, (85) for fishes]. Indeed, anthropogenic noise overlaps with the frequency band of hearing of marine animals across increasingly broad areas of the ocean (86-88) (Fig. 2). Masking of signals from conspecifics or environmental cues indicating the presence of prey or predators may result in loss of social cohesion, missed opportunities for feeding, or failure to avoid a predator (25).

The frequency content of vessel noise (Fig. 2) overlaps considerably with the hearing ranges of marine fauna (20), particularly those with sensitivity in relatively low-frequency ranges [e.g., fishes, some marine mammals, and reptiles $(20,25,89-91)]$, where most of the noise energy lies. Shipping noise has been reported to disrupt traveling, foraging, socializing, communicating, resting, and other behaviors in marine mammals (84); attenuate antipredator behavior of young fishes, leading to increased mortality and reduced ability to learn to avoid predators in future encounters (79); and impact the settlement and development of invertebrates (85). A concurrent increase in anthrophony and decrease in biophony with habitat degradation and declines in populations of marine species also likely affects onshore 
larval movement patterns, and hence settlement success, across a range of species.

Given the potential for anthropogenic noise to detrimentally affect marine animals (82, 92, 93), we examined the robustness and consistency of the evidence for impacts of anthrophony and other human alterations to ocean soundscapes on marine animals through a systematic assessment of the results on this topic presented in the published literature (94). This generated a total of 538 studies that attempted to quantify the effects of anthropogenic noise and perturbations of soundscapes on marine animals. We adopted the confidence scale of the Intergovernmental Panel on Climate Change (IPCC) (95) to reflect the robustness of the evidence supporting various statements on the extent of the impacts.

There was high confidence that anthropogenic noise negatively affected marine animals (Fig. 4 and table S4). The evidence was strongest for marine mammals, for which 85 to $94 \%$ of quantitative studies found significant effects, with 82 and $81 \%$ of studies finding significant impacts on fishes and invertebrates, respectively, and the two studies available for reptiles and one of the two studies on marine birds reporting significant impacts on these animals (Fig. 4 and table S4). Noise from vessels (94.9\% report significant impacts), sonars (90\%), and acoustic deterrent devices (91\%) negatively affects marine animals, as does noise from energy ( $8.23 \%$ of studies) and construction infrastructure (82.3\%) and seismic surveys (74.4\%) (Fig. 4 and table S4). Available data provide ample evidence that noise pollution compromises hearing ability (90.6\% of studies report significant impacts), induces physiological changes (91.2\%), and elicits evasive actions and displaces marine animals (83.9\%) (Fig. 4 and table S4). By contrast, evidence for impacts of anthropogenic noise on mortality and fitness of marine animals is weaker, with 35.2 and $50 \%$ of studies reporting significant impacts, respectively (Fig. 4 and table S4). All quantitative studies conducted thus far provide evidence that changes in biophony reduce the settlement of marine larvae, but the number of quantitative studies testing impacts on settlement remains limited ( $n=7$; table $\mathrm{S} 4$ ).

Our assessment revealed that despite the large volume of literature on the impacts of anthropogenic noise on marine animals, there is a paucity of quantitative assessments for diving marine reptiles and seabirds and only a limited number of studies on pinnipeds and sirenians (Fig. 4). Likewise, the evidence supporting that changes in biophony resulting from habitat degradation reduce the settlement of marine larvae on preferred habitats was weakened by the few studies available. The evidence for impacts on animals exposed to multiple sources of anthropogenic noise was
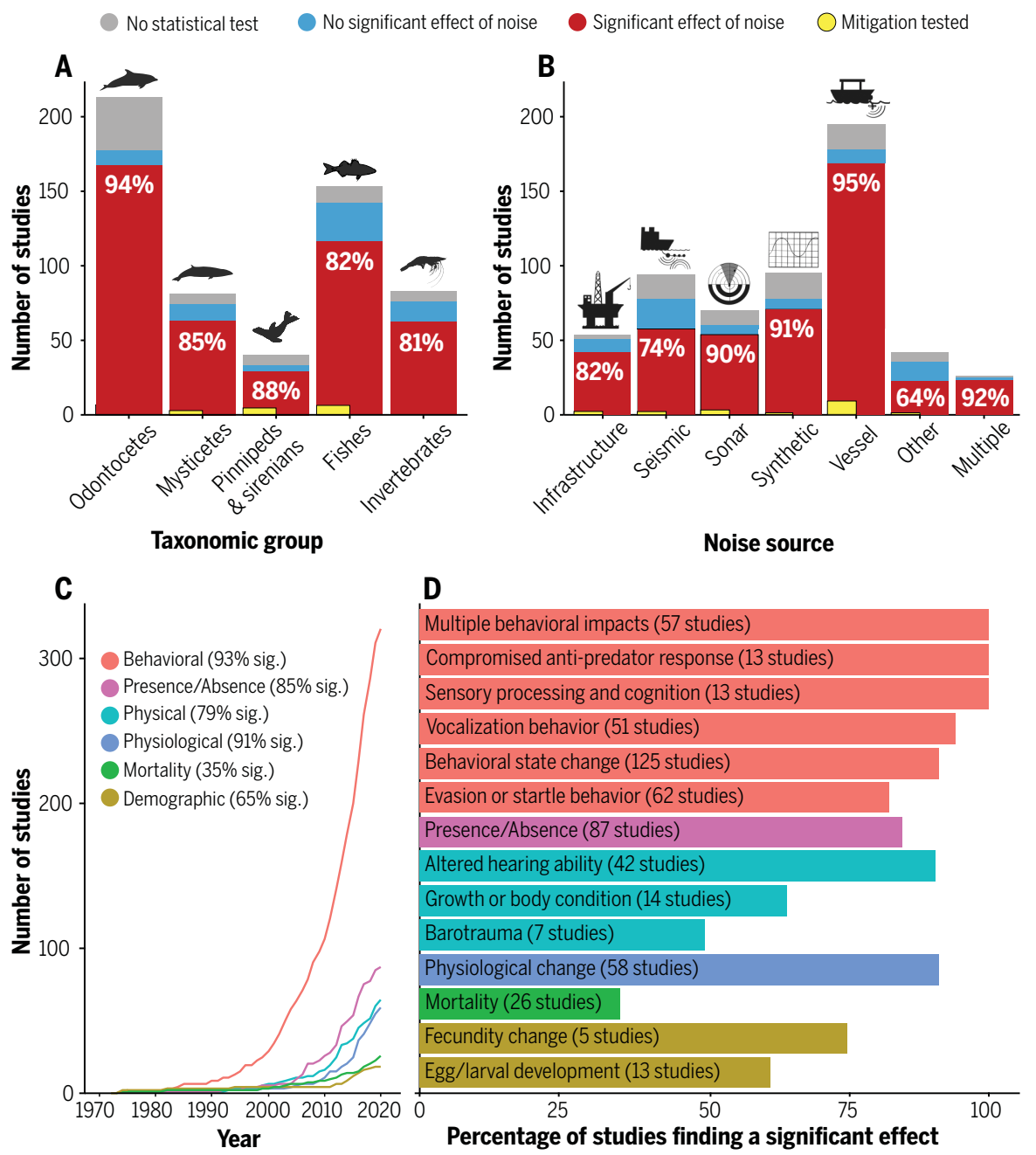

D

Noise source

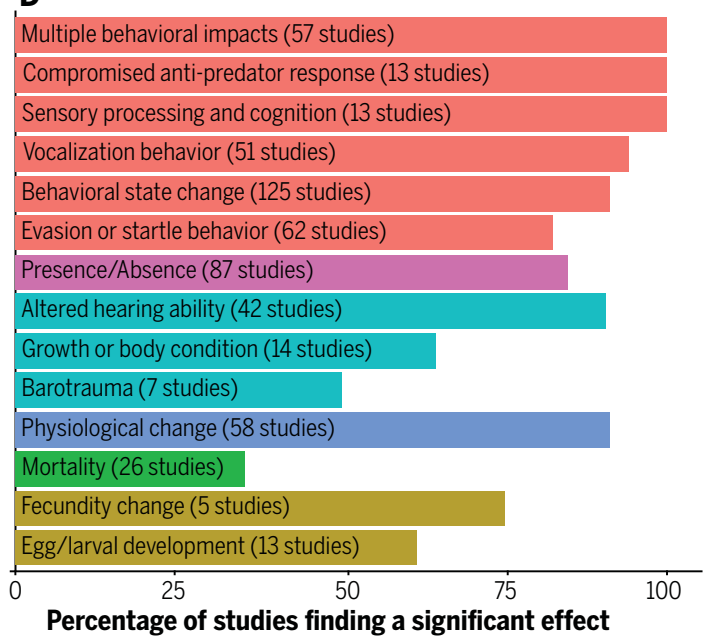

Fig. 4. Synthesis of the negative impacts of noise pollution on marine animals present in the literature. The estimates provided here derive from a systematic literature review [(74), compare supplementary materials]. (A and B) Total number of studies found, split by (A) taxa (excluding birds and reptiles, which together accounted for only six studies) and (B) noise source. Colors indicate the proportion of different statistical outcomes (red, significant negative effect of noise; blue, no significant effect of noise; gray, no statistical test) and the proportion of studies that seek to directly test the impact of noise-mitigation strategies such as bubble curtains and altered engine types (yellow). White numbers indicate the percentage of studies with a statistical test (red plus blue) that find a significant effect of noise (red). (C) Cumulative frequency curves over time of all studies, split by effect category. Searches were carried out from 1900 to 2020, but no records that met the criteria were found before 1973. (D) The percentage of studies in each subcategory that found a significant effect of noise, calculated as a fraction of the total number of studies with a statistical test.

also small, limiting the assessment for cumulative impacts. In addition, we found a very limited number of studies testing the effectiveness of mitigation measures, which makes it difficult to provide confidence on their performance. This may preclude these mitigation measures from being adopted by national and international policies aimed at reducing the impacts of anthropogenic noise on marine life. The gaps identified in our systematic review underscore areas where research efforts should focus to provide a comprehensive understanding of the impact of anthropogenic noise on marine animals, integrate these impacts to assess population-level consequences from chronic exposure to anthropogenic noise, and deliver effective mitigation measures.

In addition to controlled experiments, global disruptions offer an opportunity for serendipitous observations of the effect of anthropogenic noise on marine life at scale. For instance, reduced ship traffic in the Bay of Fundy, Canada, after the events of 11 September 2001 resulted in a 6 -dB decrease in underwater noise, particularly at frequencies less than $150 \mathrm{~Hz}$, with some evidence suggesting that this reduced stress in right whales (Eubalaena glacialis) (96). Likewise, strategies to combat 
COVID-19 infections, which involved confinement of about $58 \%$ of the global human population, have also provided ample evidence of an unusual expansion of the movements of marine mammals and sharks to what were previously busy, noisy waterways, such as harbors and coastal urban areas, where they are not regularly seen (97). This unusual behavior has been linked to reduced anthropogenic noise during human confinement $(98,99)$.

Marine animals may recover from and cope with intense anthropogenic noise through avoidance behavior or habituation $(100,101)$. The former behavior is a common response of marine animals to potentially damaging or disruptive levels of anthrophony but may displace species from important foraging grounds (100) and is not always possible for species that have high site fidelity and small biogeographical ranges, such as the critically endangered Maui dolphin (Cephalorhynchus hectori maui) (102), or slow-moving species, like benthic invertebrates, which have a limited scope to avoid noise. When hearing damage occurs from loud noises, fish may recover better than marine mammals because hair cells regrow in fish but are unlikely to regenerate in mammals (103). Avoidance behavior by fish in response to the approaching sound of fishing vessels is well documented (103). However, this may also be induced by sounds from recreational boats, resulting in flight responses and interruption of foraging, reproductive, or vocalizing activities (104). Conversely, it is possible that some predatory marine mammals and large fishes may use the sound of vessels as a "dinner bell" alerting of opportunities to depredate catch from fishing boats $(105,106)$. These examples provide evidence for behavioral plasticity or acclimation but do not provide evidence for evolutionary adaptation, which requires observational time scales that have not yet been achieved in soundscape ecology.

Marine mammals may adapt to anthrophony, but the long life span and large home ranges of many marine mammals render assessment of adaptations to noise challenging. For instance, some mammals-such as killer whales (Orcinus orca), right whales (Eubalaena spp.), and Guiana dolphins (Sotalia guianensis) and fishes have been shown to alter the source level or frequency of vocalizations in order to be heard, a phenomenon known as the Lombard or cocktail party effect (107-110). Habituation, in the form of increasing tolerance, has been demonstrated for some species of marine mammals and fishes $(101,111)$. In some situations, habituation may be considered a reduced response to stimuli that have no biological importance on the individual being observed (112), although disturbance involving a sensory modality that is so fundamental to most marine animals would not often be considered inconsequential.

Although our assessment shows that anthropogenic noise detrimentally affects marine animals, a lack of global syntheses of data has resulted in it being typically ignored in reviews of cumulative and/or global impacts of anthropogenic stressors on marine life $(3,5,6,113)$ and consequently by the high-level policy initiatives (e.g., UNCBD, UNCLOS, UN SDGs) that these analyses inform. For instance, the draft of the UN Law of the Sea "BBNJ" Agreement on Biodiversity in Areas Beyond National Jurisdiction (114) does not mention noise among cumulative impacts, despite mandating an environmental impact assessment of activities in the high seas and the fact that anthropogenic noise was discussed at its 19th session of the process in June 2018. The last assessments of climate change impacts by the IPCC (115) have yet to acknowledge the impacts that climate change has on ocean soundscapes, whereas the recent IPCC report on oceans and the cryosphere acknowledges noise only in the context of increased human operations in the Arctic Ocean (116). Our review of existing evidence (Fig. 4) shows that anthropogenic noise should be included in assessments of cumulative pressures on marine ecosystems. Encouragingly, the Intergovernmental Science-Policy Platform on Biodiversity and Ecosystem Services (IPBES) assessment acknowledges the role of shipping noise as a pollutant affecting marine life (117), but it makes no attempt to rank its contribution compared with other human impacts in the context of multiple stressors in the marine environment.

\section{Pathways to healthy ocean soundscapes}

Most anthrophony is "noise" in a biological sense, because it is an unnatural and unwanted signal. The evidence reviewed here shows that the impacts of human alterations to ocean soundscapes are pervasive across all ocean areas and detrimentally affect marine life (Fig. 4 and table S4). Anthropogenic noise is thus a pollutant that cannot be ignored and must be addressed in policies to mitigate human impacts on the oceans. This is particularly urgent given the growing focus on the ocean-based economy, which is forecasted to double its contribution to global gross domestic product by 2030 (118). This economy includes many new industries, such as deep-sea mining, that may be major sources of underwater noise. A "business-as-usual" development of the ocean-based economy will inevitably lead to ever-increasing noise from more shipping, coastal development, seismic surveys, military operations, dredging, pile driving, and deep-sea mining, likely contributing to increasing impacts on marine biota (Fig. 4). Yet, the High Level Panel for a Sustainable Ocean
Economy (www.oceanpanel.org) has not considered anthropogenic noise in either of the Blue Papers addressing different dimensions of actions required to achieve SDG14 (www. oceanpanel.org/blue-papers), including that on integrated ocean management (119). The postponement, owing to COVID-19, of the UN Oceans Conference to 2021 provides an opportunity to consider the evidence summarized here, showing that the contribution of noise pollution to the declining status and health of ocean ecosystems is likely substantial [Fig. 4; (120)]. This is particularly timely, given that 2020-and now, because of COVID19, 2021-is the International Year of Sound (sound2020.org). There are, however, solutions that can lead to healthier ocean soundscapes in the context of a sustainable ocean economy.

Improved human stewardship of ocean soundscapes requires regulatory frameworks designed to manage sound within exclusive economic zones and the high seas and promote the deployment of available technological solutions to reduce noise introduced by human operations in the marine environment. Because species-sensitivity distribution models (120) have not yet been generated, alternative approaches for the regulation of anthropogenic noise must be developed. However, unlike other sources of pollution, anthropogenic noise is not persistent in the environment once sources are removed. Consequently, legislative actions to reduce anthropogenic noise and incentivize the deployment of existing technological solutions can have near-immediate, positive effects.

It may be easier to instigate noise reduction of activities that produce sound as a byproduct (e.g., shipping, construction), rather than intentionally (e.g., seismic surveys, military activities), through technological and/or regulatory measures, as demonstrated by recent progress in the shipping industry. In 2014, the International Maritime Organization approved voluntary guidelines for reducing underwater noise from commercial ships (www.imo. org/en/MediaCentre/HotTopics/Pages/Noise. aspx). These guidelines focused on design features that could reduce the primary sources of underwater noise, namely the propellers, hull form, and on-board machinery. Following these guidelines, in 2015, Maersk underwent a retrofit of five large container ships and found that reducing propeller cavitation decreased low-frequency sound pressure levels by 6 to $8 \mathrm{~dB}$ while improving fuel efficiency (121). In addition, the growing use of advanced materials, such as fiber-reinforced polymer composites, which have good dampening properties and are also lighter-thereby requiring less energy for propulsion-can also help to reduce ship noise. Another potential noise-reduction method is the use of electric motors which, with the development of solar power and 
battery storage, are increasingly installed on larger vessels (122). Although such technological improvements are promising, it is the ship-building companies, not necessarily the shipping companies, that need to adopt them, and there is currently no regulatory mechanism to incentivize a transition (123).

The cross-boundary nature of marine ecosystems and some sound sources (e.g., shipping) means that international cooperation is key. Yet, a review of 10 major international agreements that address noise (124) showed that all but one are voluntary in nature or offer both binding and nonbinding options for member nations; the exception is the European Union's Marine Strategy Framework Directive (MSFD), which explicitly includes noise as a stressor and mandates that European Union member states monitor and mitigate noise pollution as part of their efforts to obtain "good environmental status." A likely reason for the noncommittal nature of international agreements that address marine noise is the absence of a compelling assessment of the evidence of impacts, which we now provide (Fig. 4). Therefore, we hope that the strong evidence summarized here will increase the ambition of national and international policies that regulate marine noise to achieve soundscapes conducive to healthy oceans across exclusive economic zones and the high seas.

Meanwhile, regulating the speed and routes of ships can help reduce noise and/or divert impacts away from biologically sensitive areas. For example, reducing steaming speeds for noisy vessels in the major shipping route(s) in the eastern Mediterranean from 15.6 to 13.8 knots led to an estimated 50\% reduction in the broadband noise from these vessels between 2007 and 2013 (125). A recent assessment estimated that half of the total noise radiated by the shipping fleet comes from just $15 \%$ of the ships, particularly those with source levels above $179 \mathrm{~dB}$ re $1 \mu \mathrm{Pa}$ at $1 \mathrm{~m}$ [i.e., relative to the reference pressure of $1 \mu \mathrm{Pa}$ root mean square (126)]. Thus, a targeted approach with focused incentives could substantially reduce shipping noise. Marine construction, particularly for offshore wind farms, is achieving rapid advancements in noise-dampening technology. Acoustic barriers like bubble curtains and noise-abating sleeves have been introduced in some European wind farms and can reduce sound from pile driving by up to $15 \mathrm{~dB}$ (127). Indeed, both the European Union's MSFD and the U.S. National Marine Fisheries Service encourage the use of such technologies. Finally, the E\&P Sound and Marine Life Programme, funded by a number of oil and gas companies, has invested in developing alternative technologies to seismic air guns (www.soundandmarinelife.org/). Marine vibrators ("vibroseis") produce sounds that are nonimpulsive and more narrow band in frequency than typical seismic air guns, potentially removing some of the more harmful acoustic attributes. Several companies are developing prototype vibroseis technology to be mounted on submarine vehicles that would roam the seafloor. These vehicles will use hydraulic systems to generate force waves that penetrate the sediments and deliver the required data while avoiding impacts on animals in the water column (128). As environmental constraints and impacts of deep-sea mining are discussed, there is an opportunity to design instruments and procedures that avoid impacts from noise before commercial operations begin (128).

Mitigating climate change in accordance with the most ambitious goals set by the Paris Agreement (https://unfccc.int/process-andmeetings/the-paris-agreement/the-parisagreement) will also help reduce further impacts from climate change on geophony and biophony. However, the recent IPCC assessment of climate change impacts on oceans and the cryosphere indicates that sea ice will continue to decline, affecting soundscape features, and coral reefs will continue to degrade even if those climate goals are met (116), affecting biophonic components.

Sound is a fundamental component of the sensory environment of marine ecosystems, with animals across a broad range of taxafrom jellyfish to marine mammals-perceiving and using sound throughout their life history. Global industrialization of the ocean has led to the rise of anthrophony, whereas human impacts on marine species and ecosystems and the climate system have led to a decline in biophony and alterations to geophony. Substantially modified ocean soundscapes, in turn, have widespread impacts on the ecology of the Anthropocene ocean. These impacts are pervasive, affecting animals at all taxonomic and trophic levels, and compounded with impacts from other stressors, such as ocean warming, acidification, habitat loss, and overfishing. Changing ocean soundscapes have become the neglected "elephant in the room" of global ocean change. In an era when societies increasingly look to the "blue economy" as a source of resources and wealth, it is essential that ocean soundscapes be responsibly managed to ensure the sustainable use of the ocean. Solutions to mitigate anthropogenic noise, both in terms of policy and technological measures, are becoming available but remain challenging $(123,124)$. Incorporation of these solutions in internationally binding conventions would pave the way for ocean soundscapes that support healthier ecosystems under a sustainable ocean economy.

\section{REFERENCES AND NOTES}

1. International Organization for Standardization (ISO) "Underwater acoustics-Terminology" (ISO 18405:2017, ISO, 2017).
B. C. Pijanowski, A. Farina, S. H. Gage, S. L. Dumyahn, B. L. Krause, What is soundscape ecology? An introduction and overview of an emerging new science. Landsc. Ecol. 26, 1213-1232 (2011). doi: 10.1007/s10980-011-9600-8

3. B. S. Halpern et al., A global map of human impact on marine ecosystems. Science 319, 948-952 (2008). doi: 10.1126/ science.1149345; pmid: 18276889

4. P. W. Boyd, Beyond ocean acidification. Nat. Geosci. 4, 273-274 (2011). doi: 10.1038/ngeo1150

5. C. M. Duarte, Global change and the future ocean: A grand challenge for marine sciences. Front. Mar. Sci. 1, 1-16 (2014) doi: 10.3389/fmars.2014.00063

6. L. A. Levin, D. L. Breitburg, Linking coasts and seas to address ocean deoxygenation. Nat. Clim. Chang. 5, 401-403 (2015). doi: 10.1038/nclimate2595

7. K. E. Ingeman, J. F. Samhouri, A. C. Stier, Ocean recoveries for tomorrow's Earth: Hitting a moving target. Science 363, eaav1004 (2019). doi: 10.1126/science.aav1004: pmid: 30679339

8. R. J. Urick, Principles of Underwater Sound (McGraw Hill, ed. 3, 1983).

9. M. Solé et al., Evidence of Cnidarians sensitivity to sound after exposure to low frequency underwater sources. Sci. Rep. 6, 37979 (2016). doi: 10.1038/srep37979; pmid: 28000727

10. A. Coffin, M. W. Kelly, G. A. Manley, A. N. Popper, "Evolution of sensory hair cells" in Evolution of the Vertebrate Auditory System, R. R. Fay, G. A. Manley, Eds. (Springer, 2004), pp. 55-94.

11. G. M. Wenz, Acoustic ambient noise in the ocean: Spectra and sources. J. Acoust. Soc. Am. 34, 1936-1956 (1962). doi: 10.1121/1.1909155

12. C. S. McCreery, F. K. Duennebier, G. H. Sutton, Correlation of deep ocean noise $(0.4-30 \mathrm{~Hz})$ with wind, and the Holu Spectrum-A worldwide constant. J. Acoust. Soc. Am. 93, 2639-2648 (1993). doi: 10.1121/1.405838

13. R. P. Dziak et al., Sources and levels of ambient ocean sound near the Antarctic Peninsula. PLOS ONE 10, e0123425 (2015). doi: 10.1371/journal.pone.0123425; pmid: 25875205

14. B. M. Howe et al., Observing the oceans acoustically. Front. Mar. Sci. 6, 426 (2019). doi: 10.3389/fmars.2019.00426

15. M. Tolstoy, D. R. Bohnenstiehl, E. Chapp, "Long range acoustic propagation of high frequency energy in the Indian Ocean from icebergs and earthquakes", in Proceedings of the 26th Seismic Research Review: Trends in Nuclear Explosion Monitoring, Volume II (National Nuclear Security Administration, Air Force Research Laboratory, 2004), pp. 568-578.

16. J. V. Locascio, D. A. Mann, Effects of Hurricane Charley on fish chorusing. Biol. Lett. 1, 362-365 (2005). doi: 10.1098/ rsbl.2005.0309; pmid: 17148207

17. A. 0. Kasumyan, Acoustic signaling in fish. J. Ichthyol. 49, 963-1020 (2009). doi: 10.1134/S0032945209110010

18. H. E. Winn, The biological significance of fish sounds Mar. Bio-Acoustics 2, 213-231 (1964).

19. W. W. Au, M. C. Hastings, Principles of Marine Bioacoustics (Springer, 2008).

20. R. F. Thorson, M. L. Fine, Acoustic competition in the gulf toadfish Opsanus beta: Acoustic tagging. J. Acoust. Soc. Am. 111, 2302-2307 (2002). doi: 10.1121/1.1466865; pmid: 12051450

21. W. D. Halliday, M. K. Pine, A. P. H. Bose, S. Balshine, F. Juanes, The plainfin midshipman's soundscape at two sites around Vancouver Island, British Columbia. Mar. Ecol. Prog. Ser. 603 189-200 (2018). doi: 10.3354/meps12730

22. S. Rowe, J. A. Hutchings, Sound production by Atlantic cod during spawning. Trans. Am. Fish. Soc. 135, 529-538 (2006) doi: 10.1577/T04-061.1

23. B. E. Erisman, T. J. Rowell, A sound worth saving: Acoustic characteristics of a massive fish spawning aggregation. Biol. Lett. 13, 20170656 (2017). doi: 10.1098/rsbl.2017.0656; pmid: 29263130

24. J. V. Locascio, S. Burghart, D. A. Mann, Quantitative and temporal relationships of egg production and sound production by black drum Pogonias cromis. J. Fish Biol. 81 , 1175-1191 (2012). doi: 10.1111/j.1095-8649.2012.03376.x pmid: 22957862

25. C. Erbe, C. Reichmuth, K. Cunningham, K. Lucke, R. Dooling, Communication masking in marine mammals: A review and research strategy. Mar. Pollut. Bull. 103, 15-38 (2016). doi: 10.1016/j.marpolbul.2015.12.007; pmid: 26707982

26. J. A. Thomas, C. F. Moss, M. Vater, Echolocation in Bats and Dolphins (Univ. Chicago Press, 2004). 
27. I. Van Opzeeland et al., Acoustic ecology of Antarctic pinnipeds. Mar. Ecol. Prog. Ser. 414, 267-291 (2010) doi: $10.3354 /$ meps08683

28. H. Ahonen et al., The underwater soundscape in western Fram Strait: Breeding ground of Spitsbergen's endangered bowhead whales. Mar. Pollut. Bull. 123, 97-112 (2017). doi: 10.1016/j.marpolbul.2017.09.019; pmid: 28938997

29. C. W. Clark, G. C. Gagnon, Low-frequency vocal behaviors of baleen whales in the North Atlantic: Insights from IUSS detections, locations and tracking from 1992 to 1996. J. Underw. Acoust. 52, 13 (2004).

30. E. C. Garland, L. Rendell, L. Lamoni, M. M. Poole, M. J. Noad, Song hybridization events during revolutionary song change provide insights into cultural transmission in humpback whales. Proc. Natl. Acad. Sci. U.S.A. 114, 7822-7829 (2017). doi: 10.1073/pnas.1621072114; pmid: 28739940

31. R. A. Dunlop, D. H. Cato, M. J. Noad, Non-song acoustic communication in migrating humpback whales (Megaptera novaeangliae). Mar. Mamm. Sci. 24, 613-629 (2008). doi: 10.1111/j.1748-7692.2008.00208.x

32. L. Coquereau, J. Grall, J. Clavier, A. Jolivet, L. Chauvaud, Acoustic behaviours of large crustaceans in NE Atlantic coastal habitats. Aquat. Biol. 25, 151-163 (2016). doi: $10.3354 / a b 00665$

33. C. A. Radford, A. G. Jeffs, C. T. Tindle, J. C. Montgomery, Temporal patterns in ambient noise of biological origin from a shallow water temperate reef. Oecologia 156, 921-929 (2008). doi: 10.1007/s00442-008-1041-y; pmid: 18461369

34. A. Lillis, T. A. Mooney, Snapping shrimp sound production patterns on Caribbean coral reefs: Relationships with celestial cycles and environmental variables. Coral Reefs 37, 597-607 (2018). doi: 10.1007/s00338-018-1684-z

35. E. Staaterman et al., Celestial patterns in marine soundscapes. Mar. Ecol. Prog. Ser. 508, 17-32 (2014). doi: $10.3354 /$ meps10911

36. M. J. G. Parsons, "An investigation into active and passive acoustic techniques to study aggregating fish species," thesis, Curtin University (2010).

37. J. C. Montgomery, A. Jeffs, S. D. Simpson, M. Meekan, C. Tindle, Sound as an orientation cue for the pelagic larvae of reef fishes and decapod crustaceans. Adv. Mar. Biol. 51. 143-196 (2006). doi: 10.1016/S0065-2881(06)51003-X; pmid: 16905427

38. M. H. Saucier, D. M. Baltz, Spawning site selection by spotted seatrout, Cynoscion nebulosus, and black drum, Pogonias cromis, in Louisiana. Environ. Biol. Fishes 36, 257-272 (1993). doi: 10.1007/BF00001722

39. H. K. Mok, R. G. Gilmore, Analysis of sound production in estuarine aggregations of Pogonias cromis, Bairdiella chrysoura, and Cynoscion nebulosus (Sciaenidae). Bull. Inst. Zool. Acad. Sin. 22, 157-186 (1983)

40. A. A. Myrberg, J. Y. Spires, Sound discrimination by the bicolor damselfish, Eupomacentrus partitus. J. Exp. Biol. 57, 727-735 (1972).

41. J. Sueur, S. Pavoine, O. Hamerlynck, S. Duvail, Rapid acoustic survey for biodiversity appraisal. PLOS ONE 3, e4065 (2008). doi: 10.1371/journal.pone.0004065; pmid: 19115006

42. S. D. Simpson, M. Meekan, J. Montgomery, R. McCauley, A. Jeffs, Homeward sound. Science 308, 221 (2005). doi: 10.1126/science.1107406; pmid: 15821083

43. C. A. Radford, J. A. Stanley, C. T. Tindle, J. C. Montgomery, A. G. Jeffs, Localised coastal habitats have distinct underwater sound signatures. Mar. Ecol. Prog. Ser. 401 21-29 (2010). doi: 10.3354/meps08451

44. F. Bertucci, E. Parmentier, G. Lecellier, A. D. Hawkins, D. Lecchini, Acoustic indices provide information on the status of coral reefs: An example from Moorea Island in the South Pacific. Sci. Rep. 6, 33326 (2016). doi: 10.1038/ srep33326; pmid: 27629650

45. E. Staaterman, Do bioacoustic conditions reflect species diversity? A case study from four tropical marine habitats. J. Acoust. Soc. Am. 141, 3937-3938 (2017). doi: 10.1121/ 1.4988913

46. E. V. Kennedy, M. W. Holderied, J. M. Mair, H. M. Guzman S. D. Simpson, Spatial patterns in reef-generated noise relate to habitats and communities: Evidence from a Panamanian case study. J. Exp. Mar. Biol. Ecol. 395, 85-92 (2010). doi: 10.1016/j.jembe.2010.08.017

47. S. Elise et al., Assessing key ecosystem functions through soundscapes: A new perspective from coral reefs. Ecol. Indic 107, 105623 (2019). doi: 10.1016/j.ecolind.2019.105623

48. N. Pieretti, M. Lo Martire, A. Farina, R. Danovaro, Marine soundscape as an additional biodiversity monitoring tool: A case study from the Adriatic Sea (Mediterranean Sea). Ecol. Indic. 83, 13-20 (2017). doi: 10.1016/j.ecolind.2017.07.011

49. B. J. Estabrook, D. W. Ponirakis, C. W. Clark, A. N. Rice, Widespread spatial and temporal extent of anthropogenic noise across the northeastern Gulf of Mexico shelf ecosystem. Endanger. Species Res. 30, 267-282 (2016). doi: 10.3354 /esr00743

50. J. A. Hildebrand, Anthropogenic and natural sources of ambient noise in the ocean. Mar. Ecol. Prog. Ser. 395, 5-20 (2009). doi: 10.3354/meps08353

51. D. Malakoff, A push for quieter ships. Science 328 , 1502-1503 (2010). doi: 10.1126/science.328.5985.1502; pmid: 20558702

52. J. L. Miksis-Oldsa, S. M. Nichols, Is low frequency ocean sound increasing globally? J. Acoust. Soc. Am. 139, 501-511 (2015) .doi: 10.1121/1.4938237

53. C. Erbe et al., Underwater noise from airplanes: An overlooked source of ocean noise. Mar. Pollut. Bull. 137. 656-661 (2018). doi: 10.1016/j.marpolbul.2018.10.064; pmid: 30503480

54. A. E. Newhall et al., Monitoring the acoustic effects of pile driving for the first offshore wind farm in the United States. J. Acoust. Soc. Am. 139, 2181 (2016). doi: 10.1121/1.4950483

55. T. Pangerc, P. D. Theobald, L. S. Wang, S. P. Robinson, P. A. Lepper, Measurement and characterisation of radiated underwater sound from a $3.6 \mathrm{MW}$ monopile wind turbine. J. Acoust. Soc. Am. 140, 2913-2922 (2016). doi: 10.1121/ 1.4964824; pmid: 27794307

56. C. Erbe, C. McPherson, Underwater noise from geotechnical drilling and standard penetration testing. J. Acoust. Soc. Am. 142, EL281-EL285 (2017). doi: 10.1121/1.5003328; pmid: 28964046

57. C. Erbe, R. McCauley, C. McPherson, A. Gavrilov, Underwater noise from offshore oil production vessels. J. Acoust. Soc. Am. 133, EL465-EL470 (2013). doi: 10.1121/1.4802183: pmid: 23742441

58. K. J. Reine, D. Clarke, C. Dickerson, Characterization of underwater sounds produced by hydraulic and mechanical dredging operations. J. Acoust. Soc. Am. 135, 3280-3294 (2014). doi: 10.1121/1.4875712; pmid: 24907792

59. C. Erbe, M. Parsons, A. J. Duncan, K. Allen, Underwater acoustic signatures of recreational swimmers, divers, surfers and kayakers. Acoust. Aust. 44, 333-341 (2016). doi: 10.1007/s40857-016-0062-7

60. C. Erbe, M. Parsons, A. Duncan, S. K. Osterrieder, K. Allen, Aerial and underwater sound of unmanned aerial vehicles (UAV). J. Unmanned Veh. Syst. 5, 92-101 (2017). doi: 10.1139/juvs-2016-0018

61. C. Erbe, Underwater noise of small personal watercraft (jet skis). J. Acoust. Soc. Am. 133, EL326-EL330 (2013). doi: 10.1121/1.4795220; pmid: 23556699

62. T. A. C. Gordon et al., Habitat degradation negatively affects auditory settlement behavior of coral reef fishes. Proc. Natl. Acad. Sci. U.S.A. 115, 5193-5198 (2018). doi: 10.1073/ pnas.1719291115; pmid: 29712839

63. J. Butler, J. A. Stanley, M. J. Butler IV, Underwater soundscapes in near-shore tropical habitats and the effects of environmental degradation and habitat restoration. J. Exp. Mar. Biol. Ecol. 479, 89-96 (2016). doi: 10.1016/ i.jembe.2016.03.006

64. T. Rossi, S. D. Connell, I. Nagelkerken, The sounds of silence: Regime shifts impoverish marine soundscapes. Landsc. Ecol. 32, 239-248 (2017). doi: 10.1007/s10980-016-0439-x

65. K. D. Seger, J. L. Miksis-Olds, Acoustic documentation of temperate odontocetes in the Bering and Chukchi Seas. Mar. Mamm. Sci. 35, 1099-1111 (2019). doi: 10.1111/mms.12577

66. J. Butler, M. J. Butler IV, I. V. H. Gaff, Snap, crackle, and pop: Acoustic-based model estimation of snapping shrimp populations in healthy and degraded hard-bottom habitats. Ecol. Indic. 77, 377-385 (2017). doi: 10.1016/ j.ecolind.2017.02.041

67. G. E. Davis et al., Exploring movement patterns and changing distributions of baleen whales in the western North Atlantic using a decade of passive acoustic data. Glob. Change Biol. 26, 4812-4840 (2020). doi: 10.1111/ gcb.15191; pmid: 32450009

68. W. Munk, The sound of climate change. Tellus A 63, 190-197 (2011). doi: 10.1111/j.1600-0870.2010.00494.x

69. A. J. Poulsen, H. Schmidt, Acoustic noise properties in the rapidly changing Arctic Ocean. Proc. Mtgs. Acoust. 28, 070005 (2016). doi: 10.1111/j.1600-0870.2010.00494.x

70. S. Menze, D. P. Zitterbart, I. van Opzeeland, O. Boebel, The influence of sea ice, wind speed and marine mammals on
Southern Ocean ambient sound. R. Soc. Open Sci. 4, 160370 (2017). doi: 10.1098/rsos.160370; pmid: 28280544

71. J. Nystuen, J. Miksis-Olds, Soundscapes under sea ice: Can we listen for open water? J. Acoust. Soc. Am. 127, 1728 (2010). doi: 10.1121/1.3383439

72. K. C. Hester, E. T. Peltzer, W. J. Kirkwood, P. G. Brewer, Unanticipated consequences of ocean acidification: A noisier ocean at lower pH. Geophys. Res. Lett. 35, L19601 (2008). doi: 10.1029/2008GL034913

73. T. Ilyina, R. E. Zeebe, P. G. Brewer, Future ocean increasingly transparent to low-frequency sound owing to carbon dioxide emissions. Nat. Geosci. 3, 18-22 (2010) doi: 10.1038/ngeo719

74. H. R. Harding, T. A. C. Gordon, M. N. Havlik, M. Predragovic, R. P. Devassy, A. N. Radford, S. D. Simpson, C. M. Duarte, A systematic literature assessment on the effects of humanaltered soundscapes on marine life [Dataset]. Zenodo (2020); https://www.doi.org/10.5281/zenodo.4080965.

75. F. Ladich, Sound communication in fishes and the influence of ambient and anthropogenic noise. Bioacoustics 17, 34-38 (2008). doi: 10.1080/09524622.2008.9753755

76. A. N. Popper, M. C. Hastings, The effects of human-generated sound on fish. Integr. Zool. 4, 43-52 (2009). doi: 10.1111/ j.1749-4877.2008.00134.x; pmid: 21392276

77. H. Slabbekoorn et al., A noisy spring: The impact of globally rising underwater sound levels on fish. Trends Ecol. Evol. 25, 419-427 (2010). doi: 10.1016/j.tree.2010.04.005; pmid: 20483503

78. A. N. Radford, E. Kerridge, S. D. Simpson, Acoustic communication in a noisy world: Can fish compete with anthropogenic noise? Behav. Ecol. 25, 1022-1030 (2014). doi: 10.1093/beheco/aru029

79. S. D. Simpson et al., Anthropogenic noise increases fish mortality by predation. Nat. Commun. 7, 10544 (2016). doi: 10.1038/ncomms10544; pmid: 26847493

80. E. P. Walsh, G. Arnott, H. P. Kunc, Noise affects resource assessment in an invertebrate. Biol. Lett. 13, 20170098 (2017). doi: 10.1098/rsbl.2017.0098; pmid: 28404823

81. J. L. Fewtrell, R. D. McCauley, Impact of air gun noise on the behaviour of marine fish and squid. Mar. Pollut. Bull. 64 984-993 (2012). doi: 10.1016/j.marpolbul.2012.02.009 pmid: 22385754

82. H. P. Kunc, K. E. McLaughlin, R. Schmidt, Aquatic noise pollution: Implications for individuals, populations, and ecosystems. Proc. Biol. Sci. 283, 20160839 (2016). doi: 10.1098/rspb.2016.0839; pmid: 27534952

83. W. J. Richardson, C. R. Greene Jr., C. I. Malme, D. H. Thomson, Marine Mammals and Noise (Academic Press, 1995).

84. C. Erbe et al., The effects of ship noise on marine mammalsA review. Front. Mar. Sci. 6, 606 (2019). doi: 10.3389/ fmars.2019.00606

85. A. D. Hawkins, A. E. Pembroke, A. N. Popper, Information gaps in understanding the effects of noise on fishes and invertebrates. Rev. Fish Biol. Fish. 25, 39-64 (2015). doi: 10.1007/ s11160-014-9369-3

86. C. Erbe, R. Williams, D. Sandilands, E. Ashe, Identifying modeled ship noise hotspots for marine mammals of Canada's Pacific region. PLOS ONE 9, e89820 (2014). doi: 10.1371/ journal.pone.0089820; pmid: 24598866

87. A. Nikolopoulos, P. Sigray, M. Andersson, J. Carlström, E. Lalander, "BIAS Implementation Plan - Monitoring and assessment guidance for continuous low frequency sound in the Baltic Sea" (BIAS LIFE11 ENV/SE/841, Swedish Defence Research Agency, 2016); https://biasproject.files.wordpress. com/2013/11/bias-implementation-plan.pdf.

88. N. D. Merchant et al., Impulsive noise pollution in the Northeast Atlantic: Reported activity during 2015-2017. Mar. Pollut. Bull. 152, 110951 (2020). doi: 10.1016/ j.marpolbul.2020.110951

89. G. A. Manley, Cochlear mechanisms from a phylogenetic viewpoint. Proc. Natl. Acad. Sci. U.S.A. 97, 11736-11743 (2000). doi: 10.1073/pnas.97.22.11736; pmid: 11050203

90. G. A. Manley, J. A. Clack, "An outline of the evolution of vertebrate hearing organs" in Evolution of the Vertebrate Auditory System, G. A. Manley, R. R. Fay, A. N. Popper, Eds. (Springer, 2004), pp. 1-26.

91. A. Jolivet et al., Validation of trophic and anthropic underwater noise as settlement trigger in blue mussels. Sci. Rep. 6, 33829 (2016). doi: 10.1038/srep33829; pmid: 27644947

92. K. Cox, L. P. Brennan, T. G. Gerwing, S. E. Dudas, F. Juanes, Sound the alarm: A meta-analysis on the effect of aquatic noise on fish behavior and physiology. Glob. Change Biol. 24 3105-3116 (2018). doi: 10.1111/gcb.14106; pmid: 29476641 
93. M. K. Pine, A. G. Jeffs, D. Wang, C. A. Radford, The potentia for vessel noise to mask biologically important sounds within ecologically significant embayments. Ocean Coast. Manage. 127, 63-73 (2016). doi: 10.1016/j.ocecoaman.2016.04.007

94. Methods are provided in the supplementary materials.

95. H. T. Shapiro et al., "Climate change assessments: Review of the processes and procedures of the IPCC" (InterAcademy Council, Amsterdam, 2010).

96. R. M. Rolland et al., Evidence that ship noise increases stress in right whales. Proc. Biol. Sci. 279, 2363-2368 (2012). doi: 10.1098/rspb.2011.2429; pmid: 22319129

97. A. E. Bates, R. B. Primack, P. Moraga, C. M. Duarte, COVID-19 pandemic and associated lockdown as a "Global Human Confinement Experiment" to investigate biodiversity conservation. Biol. Conserv. 248, 108665 (2020). doi: 10.1016/j.biocon.2020.108665; pmid: 32549587

98. C. Rutz et al., COVID-19 lockdown allows researchers to quantify the effects of human activity on wildlife. Nat. Ecol. Evol. 4, 1156-1159 (2020). doi: 10.1038/s41559-020-1237-z; pmid: 32572222

99. D. J. M. Thomson, D. R. Barclay, Real-time observations of the impact of COVID-19 on underwater noise. J. Acoust. Soc Am. 147, 3390-3396 (2020). doi: 10.1121/10.0001271; pmid: 32486811

100. L. Pichegru, R. Nyengera, A. M. Mclnnes, P. Pistorius, Avoidance of seismic survey activities by penguins. Sci. Rep. 7, 16305 (2017). doi: 10.1038/s41598-017-16569-x; pmid: 29176687

101. P. Tixier, N. Gasco, G. Duhamel, C. Guinet, Habituation to an acoustic harassment device (AHD) by killer whales depredating demersal longlines. ICES J. Mar. Sci. 72, 1673-1681 (2015). doi: 10.1093/icesjms/fsul66

102. K. A. Forney et al..., Nowhere to go: Noise impact assessments for marine mammal populations with high site fidelity. Endanger. Species Res. 32, 391-413 (2017). doi: 10.3354/esr00820

103. J. E. Simmonds, D. M. MacLennan, Fisheries Acoustics: Theory and Practice (Wiley, 2005).

104. J. M. González Correa et al., Recreational boat traffic effects on fish assemblages: First evidence of detrimental consequences at regulated mooring zones in sensitive marine areas detected by passive acoustics. Ocean Coast. Manage. 168, 22-34 (2019). doi: 10.1016/j.ocecoaman.2018.10.027

105. J. V. Carretta, J. Barlow, Long-term effectiveness, failure rates, and "dinner bell" properties of acoustic pingers in a gillnet fishery. Mar. Technol. Soc. J. 45, 7-19 (2011). doi: 10.4031/MTSJ.45.5.3

106. J. D. Mitchell, D. L. McLean, S. P. Collin, T. J. Langlois, Shark depredation in commercial and recreational fisheries. Rev. Fish Biol. Fish. 28, 715-748 (2018). doi: 10.1007/ s11160-018-9528-z

107. C. Erbe, R. Dunlop, S. Dolman, "Effects of noise on marine mammals" in Effects of Anthropogenic Noise on Animals, H. Slabbekoorn, R. J. Dooling, A. N. Popper, R. R. Fay, Eds. (Springer, 2018), pp. 277-309.

108. M. M. Holt, D. P. Noren, V. Veirs, C. K. Emmons, S. Veirs, Speaking up: Killer whales (Orcinus orca) increase their call amplitude in response to vessel noise. J. Acoust. Soc. Am. 125, EL27-EL32 (2009). doi: 10.1121/1.3040028; pmid: 19173379

109. D. E. Holt, C. E. Johnston, Evidence of the Lombard effect in fishes. Behav. Ecol. 25, 819-826 (2014). doi: 10.1093/ beheco/aru028

110. C. Hotchkin, S. Parks, The Lombard effect and other noise-induced vocal modifications: Insight from mammalian communication systems. Biol. Rev. Camb. Philos. Soc. 88, 809-824 (2013). doi: 10.1111/brv.12026; pmid: 23442026

111. S. L. Nedelec et al., Repeated exposure to noise increases tolerance in a coral reef fish. Environ. Pollut. 216, 428-436 (2016). doi: 10.1016/j.envpol.2016.05.058; pmid: 27325546
112. L. Bejder, A. Samuels, H. Whitehead, H. Finn, S. Allen, Impact assessment research: Use and misuse of habituation, sensitisation and tolerance in describing wildlife responses to anthropogenic stimuli. Mar. Ecol. Prog Ser. 395, 177-185 (2009). doi: 10.3354/meps07979

113. S. C. Doney et al., Climate change impacts on marine ecosystems. Annu. Rev. Mar. Sci. 4, 11-37 (2012). doi: 10.1146/annurev-marine-041911-111611; pmid: 22457967

114. United Nations Convention on the Law of the Sea Preparatory Committee, "Revised draft text of an agreement under the United Nations Convention on the Law of the Sea on the conservation and sustainable use of marine biological diversity of areas beyond national jurisdiction" (United Nations, 2019); www.un.org/bbnj/ sites/www.un.org.bbnj/files/revised_draft_text_a. conf_.232.2020.11_advance_unedited_version.pdf.

115. IPCC, "2014: Climate Change 2014: Synthesis report. Contribution of Working Groups I, II and III to the fifth assessment report of the Intergovernmental Panel on Climate Change," Core Writing Team, R. K. Pachauri, L.A. Meyer, Eds. (IPCC, Geneva, 2014).

116. IPCC, "Summary for policymakers" in "IPCC Special Report on the Ocean and Cryosphere in a Changing Climate," H.-O. Pörtner et al., Eds. (IPCC, 2019)

117. IPBES, Global assessment report on biodiversity and ecosystem services," E. S. Brondizio, J. Settele, S. Díaz, H. T. Ngo, Eds. (IPBES Secretariat, Bonn, 2019).

118. Organisation for Economic Co-operation and Development (OECD), The Ocean Economy in 2030 (OECD Publishing, 2016).

119. J.-G. Winther et al., "Integrated ocean management" (World Resources Institute, 2020); www.oceanpanel.org/bluepapers/integrated-ocean-management.

120. B. S. Halpern, K. A. Selkoe, F. Micheli, C. V. Kappel, Evaluating and ranking the vulnerability of global marine ecosystems to anthropogenic threats. Conserv. Biol. 21, 1301-1315 (2007). doi: 10.1111/j.1523-1739.2007.00752.x; pmid: 17883495

121. M. Gassmann, S. M. Wiggins, J. A. Hildebrand, Deep-water measurements of container ship radiated noise signatures and directionality. J. Acoust. Soc. Am. 142, 1563-1574 (2017). doi: 10.1121/1.5001063; pmid: 28964105

122. M. J. G. Parsons, A. J. Duncan, S. K. Parsons, C. Erbe Reducing vessel noise: An example of a solar-electric passenger ferry. J. Acoust. Soc. Am. 147, 3575-3583 (2020). doi: 10.1121/10.0001264; pmid: 32486766

123. N. D. Merchant, Underwater noise abatement: Economic factors and policy options. Environ. Sci. Policy 92, 116-123 (2019). doi: 10.1016/j.envsci.2018.11.014

124. J. Lewandowski, E. Staaterman, International management of underwater noise: Transforming conflict into effective action. J. Acoust. Soc. Am. 147, 3160-3168 (2020). doi: 10.1121/ 10.0001173; pmid: 32486808

125. R. Leaper, M. Renilson, C. Ryan, Reducing underwater noise from large commercial ships: Current status and future directions. J. Ocean Technol. 9, 50-69 (2014).

126. S. Veirs, V. Veirs, R. Williams, M. Jasny, J. Wood, A key to quieter seas: half of ship noise comes from $15 \%$ of the fleet. PeerJ Preprints e26525v1 [Preprint]. 15 February 2018 doi: 10.7287/peeri.preprints.26525v1

127. M. A. Bellmann, "Overview of existing noise mitigation systems for reducing pile-driving noise" in INTERNOISE 2014 - 43rd International Congress on Noise Control Engineering: Improving the World Through Noise Control (Australian Acoustical Society, 2014), pp. 1-11.

128. B. Christiansen, A. Denda, S. Christiansen, Potential effects of deep seabed mining on pelagic and benthopelagic biota. Mar. Policy 114, 103442 (2020). doi: 10.1016/j.marpol.2019.02.014

129. A. N. N. Popper, R. R. Fay, Eds., Perspectives on Auditory Research, vol. 50 of Springer Handbook of Auditory Research (Springer, 2014).
130. A. N. Popper, R. R. Fay, Sound detection and processing by fish: Critical review and major research questions. Brain Behav. Evol. 41, 14-25 (1993). doi: 10.1159/000113821; pmid: 8431753

131. J. A. Clack, Patterns and processes in the early evolution of the tetrapod ear. J. Neurobiol. 53, 251-264 (2002) doi: 10.1002/neu.10129; pmid: 12382279

132. D. A. Mann, Z. Lu, A. N. Popper, A clupeid fish can detect ultrasound. Nature 389, 341 (1997). doi: 10.1038/38636

133. F. Ladich, R. R. Fay, Auditory evoked potential audiometry in fish. Rev. Fish Biol. Fish. 23, 317-364 (2013). doi: 10.1007/ s11160-012-9297-z; pmid: 26366046

134. C. Erbe et al., Review of underwater and in-air sounds emitted by Australian and Antarctic marine mammals. Acoust. Aust. 45 179-241 (2017). doi: 10.1007/s40857-017-0101-z

135. Y. Zhang, F. Shi, J. Song, X. Zhang, S. Yu, Hearing characteristics of cephalopods: Modeling and environmental impact study. Integr. Zool. 10, 141-151 (2015). doi: 10.1111/ 1749-4877.12104; pmid: 24920389

136. L. Chapuis, C. C. Kerr, S. P. Collin, N. S. Hart, K. L. Sanders, Underwater hearing in sea snakes (Hydrophiinae): First evidence of auditory evoked potential thresholds. J. Exp. Biol. 222, jeb198184 (2019). doi: 10.1242/jeb.198184 pmid: 31345949

137. K. J. Martin et al., Underwater hearing in the loggerhead turtle (Caretta caretta): A comparison of behavioral and auditory evoked potential audiograms. J. Exp. Biol. 215, 3001-3009 (2012). doi: 10.1242/jeb.066324; pmid: 22875768

138. L. Di lorio, C. Gervaise, V. Jaud, A. A. Robson, L. Chauvaud, Hydrophone detects cracking sounds: Non-intrusive monitoring of bivalve movement. J. Exp. Mar. Biol. Ecol. 432-433, 9-16 (2012). doi: 10.1016/i.jembe.2012.07.010

139. B. M. Casper, D. A. Mann, Field hearing measurements of the Atlantic sharpnose shark Rhizoprionodon terraenovae. J. Fish Biol. 75, 2768-2776 (2009). doi: 10.1111/ j.1095-8649.2009.02477.x; pmid: 20738522

140. H. O. Sertlek, H. Slabbekoorn, C. Ten Cate, M. A. Ainslie, Source specific sound mapping: Spatial, temporal and spectral distribution of sound in the Dutch North Sea. Environ. Pollut. 247, 1143-1157 (2019). doi: 10.1111/ j.1095-8649.2009.02477.x; pmid: 20738522

\section{ACKNOWLEDGMENTS}

The summary figure was produced by X. Pita, scientific illustrator at King Abdullah University of Science and Technology (KAUST). We thank J. Rodriguez and O. Sertlek for help with Fig. 3. Threedimensional models are from Cadnav.com. We thank $\mathrm{R}$. Jones and W. D. Halliday for useful criticism. Funding: This research was funded by KAUST through the Tarek Ahmed Juffali Research Chair in Red Sea Ecology and baseline funding to C.M.D. Author contributions: C.M.D. conceived the research; C.M.D., H.R.H., T.A.C.G., S.D.S., M.N.H M.P., R.P.D., and A.N.R. conducted the systematic analysis of the literature; and all authors contributed to the concepts, data, analysis, and writing of the manuscript and approved the submission. Competing interests: The authors declare no competing interests. Data and materials availability: All data are available in the manuscript or the supplementary materials. Compiled data is available at Zenodo (74).

\section{SUPPLEMENTARY MATERIALS}

science.sciencemag.org/content/371/6529/eaba4658/suppl/DC1 Materials and Methods

Fig. S1

Tables S1 to S3

References (141-175)

MDAR Reproducibility Checklist

10.1126/science.aba4658 


\section{Science}

\section{The soundscape of the Anthropocene ocean}

Carlos M. Duarte, Lucille Chapuis, Shaun P. Collin, Daniel P. Costa, Reny P. Devassy, Victor M. Eguiluz, Christine Erbe, Timothy A. C. Gordon, Benjamin S. Halpern, Harry R. Harding, Michelle N. Havlik, Mark Meekan, Nathan D. Merchant, Jennifer L. Miksis-Olds, Miles Parsons, Milica Predragovic, Andrew N. Radford, Craig A. Radford, Stephen D. Simpson, Hans Slabbekoorn, Erica Staaterman, Ilse C. Van Opzeeland, Jana Winderen, Xiangliang Zhang and Francis Juanes

Science 371 (6529), eaba4658.

DOI: $10.1126 /$ science.aba4658

\section{An anthropogenic cacophony}

Sound travels faster and farther in water than in air. Over evolutionary time, many marine organisms have come to rely on sound production, transmission, and reception for key aspects of their lives. These important behaviors are threatened by an increasing cacophony in the marine environment as human-produced sounds have become louder and more prevalent. Duarte et al. review the importance of biologically produced sounds and the ways in which anthropogenically produced sounds are affecting the marine soundscape.

Science, this issue p. eaba4658

ARTICLE TOOLS

SUPPLEMENTARY

MATERIALS

REFERENCES

PERMISSIONS http://science.sciencemag.org/content/371/6529/eaba4658

http://science.sciencemag.org/content/suppl/2021/02/03/371.6529.eaba4658.DC1

This article cites 153 articles, 12 of which you can access for free http://science.sciencemag.org/content/371/6529/eaba4658\#BIBL

http://www.sciencemag.org/help/reprints-and-permissions

Use of this article is subject to the Terms of Service

Science (print ISSN 0036-8075; online ISSN 1095-9203) is published by the American Association for the Advancement of Science, 1200 New York Avenue NW, Washington, DC 20005. The title Science is a registered trademark of AAAS.

Copyright (C) 2021 The Authors, some rights reserved; exclusive licensee American Association for the Advancement of Science. No claim to original U.S. Government Works 